\title{
Spanish astronomy defended
}

SIR-As a British astrophysicist who has been working in Spain during the past two years, I read with surprise and concern a statement in your "Science in Iberia" issue (Nature 324, 318; 1986) that "Astronomy appears to be a major disappointment. Despite access to the superb international facilities in the Canary Islands, very few Spanish papers appear in top journals."

This statement, insofar as it bears any relation to the real world, must be based on an outdated and therefore highly misleading set of facts. The facilities referred to were inaugurated formally in 1985 , have been in partial operation since 1984 and will not come into full operation until the late 1980 s. Anyone with even a limited understanding of research knows that publications do not appear instantly when experiments or observations are performed. A fortiori this cannot be expected to occur if there is a need to train a first generation of scientists almost from scratch before they can participate in the activities of acquisition and reduction of data, and subsequent physical interpretation. This has been the situation with Spanish astrophysicists in general, and with the Instituto de Astrofísica de Canaries (IAC, which has administrative charge of the Canary Observatories) in particular.

One would expect the publication rate to rise significantly once the first 'crop' of PhDs from research students trained in both non-Spanish and in Spanish institutes begins to turn out independent work, probably next year. It is therefore to the credit of the young Spanish astronomical community (and to the foresight of those few who planned ahead) that it has already begun to make an impact. A clear indication of this was the initiative of the editorial board of Astronomy and Astrophysics to invite Spain to become a member of this leading European journal, given the recent sharp rise in the number of Spanish publications. In 1986, for example, 15 papers from this institute alone were published in Astronomy and Astrophysics, which may be compared with the 13 from the Max Planck Institut für Astronomie at Heidelberg and 31 from the Institut d'Astrophysique in Paris, an institute with more than twice the staff of IAC. Further, it is acknowledged within the UK Science and Engineering Research Council that the quality of Spanish applications for time on the Canary Island telescopes is as high and the oversubscription rate as great as those of applications from other members of the observatories' international partners, which include the United Kingdom. I would personally wager that if present funding levels for astronomy here are not reduced, Spain will become one of the four or five leading nations in Europe within 20 years - a short time to build a tradition.

It is possible that the author of the remark quoted above was misled by a recent study in Mundo Cientifico (62, 1002; 1986), the Spanish edition of La Recherche, giving figures about astrophysical publications from Spanish institutes. This study was based on data collected before the Canary Observatories were in operation, and has in any case been severely criticized for omitting many publications from Spanish astrophysicists in international collaboratories.

\section{Instituto de Astrofísica de Canarias,}

38200 La Laguna,

Tenerife, Spain

SIR-In Nature's special issue about "Science in Iberia" the following statement appears (324, 318; 1986): “Astronomy appears to be a major disappointment. Despite access to the superb international facilities in the Canary Islands, very few Spanish papers appear in top journals."

This declaration is as serious as it is frivolous and it would be very interesting to know the source of such a negative idea.

The "superb international facilities in the Canary Islands" were inaugurated just last year by the King and Queen of Spain. While some of the telescopes commenced part-time operation in 1984, others will not even see first light until 1988 so it would surely be premature to expect abundant "Spanish papers in top journals".

The real state of affairs is that Spanish astrophysics, non-existent only 20 years ago, is beginning to enjoy a promising prestige among the international scientific community. Only 15 years ago, there was not even one chair of astrophysics at any Spanish university; now there are more than 25 professors of astrophysics. The number of $\mathrm{PhDs}$ in this field is over 50 and the universities produce more than 40 MAs in astrophysics each year. Whereas there were no institutes of astrophysics, there are now two, and nearly one hundred papers are published in international journals every year. What is more, we are expanding rapidly and production is increasing daily. But the most promising feature is that the brightest youngsters are becoming increasingly interested in astronomy.

This great leap forward has been achieved by the enthusiastic work of a handful of Spaniards backed by our European colleagues and greatly helped by international investments. Focusing, as an example, on the Canary Islands' observatories, thanks to the 20 per cent observing time plus the 5 per cent for projects in collaboration that we receive free of charge, young Spanish research groups are managing to observe with the finest modern instruments while mixing with the world's top astrophysicists. The final launching of modern astronomy in Spain is simply a matter of time. The 'Solera' (the distinctive flavour of a mature sherry) that we have lacked in astrophysics is being gained very rapidly.

Even the Minister of Education and Science and the Secretary of State for Universities and Research are well aware of the privileged situation of astrophysics in our country and their intention to pay it special attention is well known.

Instituto de Astrofísica

FranCISCO SANCHEZ

de Canarias,

38071 La Laguna,

Tenerife, Spain

\section{Civil servants}

SIR-In clarification of your story about the Plant Gene Expression Center (Nature 324, 103; 1986), Peter Quail will be an employee of the University of California in Berkeley, but our other six newly named staff members will be federal civil servants. Because the centre is a cooperative venture with the University of California system, these federal employees will probably also have faculty appointments at the Berkeley campus. Other scientists within the Agricultural Research Service have adjunct appointments with local universities.

US Department of Agriculture,

Gerald G. Still Agricultural Research Service,

Pacific Basin Area Plant

Gene Expression Center,

800 Buchanan Street,

Albany, California 94710, USA

\section{Too old at 30}

SIR-The rendering by Bill Johnstone $(324,8 ; 1986)$ of the prejudice of some faculty members (and search committees) "in favour of [the superior creativity of] people younger than 33 " is not unfamiliar to me. As a postdoc over the age of 33 , however, permit me to gather together the tatters of my creative insight and delicately point out that these gentle academicians could best perceive the strength of their peculiar logic if they applied it to themselves.

May one then expect to behold the amazing sight of a resignation en masse of the 'over-age' among these who, with selfconsistent altruism, will no doubt equally put the good of scientific progress over the feeble expression of their own fast-fading creative powers?

Department of Chemistry,

PATRICK FRANK

Stanford University,

Stanford, California 94305, USA 